\title{
El movimiento feminista estudiantil chileno de 2018: Continuidades y rupturas entre feminismos y olas globales*
}

\author{
The Chilean student feminist movement of 2018: \\ Continuities and ruptures between feminisms and global waves
}

Camila Ponce Lara**

Resumen: El año 2018 es un momento clave para el movimiento feminista a nivel mundial. En Chile, las estudiantes feministas se transforman en una marea violeta que se toma calles e instituciones luchando por una educación no sexista y terminar con el acoso sexual hacia las mujeres. Este artículo plantea que este movimiento tiene anclajes históricos y globales que se configuran de manera paralela a las demandas visibilizadas en las calles. Como hipótesis se plantea también que este movimiento representa la cuarta ola feminista. La metodología es cualitativa, con base en entrevistas en profundidad a activistas feministas y análisis de fuentes secundarias.

Palabras clave: movimiento estudiantil feminista, feminismos, estudios de juventud, movimiento feminista en Chile.

\begin{abstract}
The year 2018 was a key time for the feminist movement around the world. In Chile, feminist students transformed into a purple wave that took to the streets and took on institutions to fight for non-sexist education and put an end to sexual harassment against women. This article proposes that the movement has both historical and global foundations that are configured in parallel to the demands voiced in the streets. It also hypothesizes that this movement represents the fourth wave of feminism. This study applies a qualitative methodology based on in-depth interviews with feminist activists and the analysis of secondary sources.
\end{abstract}

Key words: student feminist movement, feminism, youth studies, feminist movement in Chile.

Recibido: 7 junio 2019 Aceptado: 30 agosto 2019

\footnotetext{
* Este artículo forma parte de la investigación Fondecyt Iniciación 11170930, financiada por Conicyt.

** Chilena. Doctora en Sociología por la École des Hautes Études en Sciences Sociales de Paris (EHESS). Es directora del Doctorado en Ciencias Sociales mención en Juventud e investigadora del Centro de estudios en Ciencias Sociales y Juventud de la Universidad Católica Silva Henríquez. Cponce1@ucsh.cl
} 


\section{Introducción al movimiento}

El año 2018 se constituye como un año relevante en materia de movimientos sociales, puesto que la sociedad chilena vio irrumpir movilizaciones creativas y que se diferenciaban de aquellas precedentes. Es claro que, de alguna manera, estas movilizaciones contenían algunas continuidades con el movimiento estudiantil de 2011; el más masivo del regreso a la democracia hasta ese momento, y que exigía un cambio al modelo neoliberal ${ }^{1}$ y la desarticulación de los denominados "enclaves autoritarios"2. Muchas de las demandas de aquel movimiento que fuera conducido en su momento por los reconocidos líderes carismáticos Camila Vallejo y Giorgio Jackson y que en la actualidad son diputados en el Congreso, siguen a la espera de cristalizarse.

En este artículo se utilizará la definición de movimiento social, elaborada por Charles Tilly y Sidney Tarrow ${ }^{3}$. Para aquello se entenderá una campaña de reivindicación sostenida en el tiempo, que utiliza representaciones repetidas para hacerse conocido a un público masivo y que se apoya de organizaciones, redes, tradiciones y solidaridades. El movimiento asociado a una campaña de reivindicación con estas características, puede manifestarse a través de: un conjunto de representaciones públicas tales como marchas, concentraciones, manifestaciones, creación de asociaciones especializadas, reuniones, declaraciones, peticiones, envío de cartas, lobby; la expresión visible de la dignidad, la unidad, la masa, del compromiso mediante el uso de ciertos colores, chapas o insignias, un desfile disciplinado, slogans cadenciosos o coros y de concentraciones frente a edificios públicos.

Por lo cual, el movimiento del cual se habla en este artículo estaba solo en una fase de latencia ${ }^{4}$ a la espera de que se generaran las condiciones necesarias para emerger, o más bien la estructura de oportunidad política, que permitieran crear los marcos para la acción colectiva $^{5}$. Así es como, en 2018, estos marcos se articularon al ritmo de un movimiento feminista global presente no solo en América Latina, sino que también en el mundo entero. En el momento que los liceos y las universidades eran ocupados por las estudiantes chilenas, en España miles de mujeres salían a las calles reclamando contra la sentencia judicial del grupo denominado "La Manada", con hashtags tales como el \#YoSíTeCreo y lemas como "no es abuso, es violación". Paralelamente, en la Argentina las mujeres se manifestaban a favor de "la legalización del aborto en todas las causales", instalando en todo el país el

\footnotetext{
1 Sandra Vera, "Cronología del conflicto: El movimiento estudiantil en Chile, 2011", Anuario del Conflicto Social 2011, 2012, 247-251; Camila Ponce, Des livres à la rue: la transformation culturelle et politique des jeunes militants chiliens à partir des mobilisations étudiantes de 2011, Paris, 2017, Tesis defendida en la École des Hautes Études en Sciences Sociales de Paris.

2 Manuel Antonio Garretón, Incomplete Democracy, North Carolina, Chapel Hill, 2003.

3 Charles Tilly y Sidney Tarrow, Politique(s) du conflit. De la grève à la révolution, Paris, Presse de Sciences Po, 2008.

4 Alberto Melucci, Social movements and the democratization of everyday life, Londres, Verso, 1988.

5 Sidney Tarrow, Struggling to reform: Social movements and policy change during cycles of protest, Center for International Studies, Cornell University, 1983; Hanspeter Kriesi, “New social movements and the new class in the Netherlands", American Journal of Sociology, 94(5), 1989, 1078-1116.
} 
"pañuelazo verde" como práctica de reivindicación y bandera de lucha, retomando el símbolo de las madres y abuelas de la plaza de mayo.

Atendiendo a ello, las movilizaciones estudiantiles de 2018 en Chile retomaron algunas de las demandas engendradas en el masivo movimiento estudiantil de 2011, pero esta vez le inscribió una impronta de lucha eminentemente feminista. Estas reivindicaciones se escucharon con más ímpetu en las marchas estudiantiles y la activación política estudiantil se sumó al dinamismo de mujeres insubordinadas contra el acoso en las distintas universidades y la exigencia una educación no sexista. Las estudiantes hicieron masivas marchas y creativas performances contra el acoso y la violencia de género en espacios públicos, tales como avenidas, plazas o edificios de instituciones. Efectivamente, las denuncias de acoso no eran algo nuevo en el mundo académico y hace bastante tiempo existían rumores sobre diferentes profesores que habían incurrido en acciones inapropiadas contra estudiantes. Pero en 2018, esos reclamos que se escuchaban como rumores de pasillo, en las distintas escuelas y facultades universitarias, se hicieron más fuertes y se plasmaron en distintos diarios de circulación nacional. Así fue, como fueron expuestos los casos de acoso de la Escuela de Historia, de la Facultad de Humanidades de la Universidad de Chile6. Con ello inició la ola feminista con decenas de acusaciones de profesores en las universidades chilenas. Con el paso de los meses, el movimiento creció rápidamente y se extendió a las distintas ciudades del país. Las denuncias y demandas por protocolos contra el acoso se emplazaron en las principales universidades del país, como también en decenas de liceos emblemáticos de estudiantes secundarios -tanto de hombres, de mujeres y mixtos, tales los casos del Liceo N¹ Javiera Carrera, el Liceo Tajamar o del Liceo 7 de Niñas de Providencia, como también en otros establecimientos educacionales menos conocidos 7 . De este modo, la primera toma feminista se inició en abril en la Universidad Austral, donde se contabilizaron más de cien denuncias por $\operatorname{acoso}^{8}$.

Las reivindicaciones feministas de lo largo y ancho del país tenían como objetivo incluir distintos asuntos, como combatir al patriarcado de las universidades chilenas, la creación y puesta en marcha de protocolos contra el acoso y la generación de una educación no sexista. Otros elementos que se esbozaron a partir de carteles en marchas e instalaciones en universidades, era la reivindicación y visibilización de las mujeres en las distintas disciplinas del conocimiento -como la ciencia y las artes- desmitificar la sexualidad

\footnotetext{
${ }^{6}$ Camila Ossandón y José Tomás Tenorio, “Sexo, mentiras y denuncias: la Facultad de Filosofía y Humanidades de la Universidad de Chile y los casos de acosos y anuncios", El Mostrador, 27 de diciembre de 2016. Consultado el 21 de abril de 2019 en: https://www.elmostrador.cl/noticias/pais/2016/12/27/sexo-mentiras-y-denunciasla-facultad-de-filosofia-y-humanidades-de-la-universidad-de-chile-y-los-casos-de-acoso-y-abusos/

7 Camila Mardones, "Movilizaciones en liceos emblemáticos”, La Tercera, 28 de mayo de 2018. Consultado el 21 de abril de 2019: https://www.latercera.com/nacional/noticia/movilizacion-liceos-emblematicos/183347/\# 8 Antonia Salas, "Universidad Austral, el plantel donde se gestó la primera toma feminista en Chile y un protocolo contra el acoso", 9 de junio de 2018: Consultado el 22 de abril del 2019: https://www.emol.com/noticias/Nacional/2018/06/09/909169/Universidad-Austral-el-plantel-donde-segesto-la-primera-toma-feminista-en-Chile-y-protocolo-contra-el-acoso.html
} 
femenina. Poco importó la misión declarada por las universidades ${ }^{9}$, puesto que estas formas de acción colectiva -las tomas- se realizaron en todo tipo de instituciones, tanto en universidades tradicionales, como la Universidad de Chile o la de Santiago; universidades regionales, como la Universidad de Concepción o la Universidad de Valparaíso; universidades con un perfil crítico, como la Academia de Humanismo Cristiano; o universidades confesionales, como la Universidad Católica de Temuco o la Universidad Católica Silva Henríquez ${ }^{10}$.

A partir de esto, investigadoras como la antropóloga Sonia Montecinos, Premio Nacional de Ciencias Sociales, han señalado que este movimiento "cuestiona los cimientos sociales de la cultura machista" de la sociedad chilena (Montecinos, 2018). Una sociedad que, al igual que el resto de las sociedades latinoamericanas, tiene bases profundamente machistas. Pero en este caso, las transformaciones han sido particularmente lentas por causa de la fortaleza de su última dictadura y su capacidad de perpetuación durante la transición a la democracia.

Frente a ese escenario, este artículo sostiene que las recientes movilizaciones estudiantiles feministas tienen un anclaje tanto histórico como global. El anclaje histórico corresponde a aquellos movimientos estudiantiles precedentes, como en el movimiento feminista de los ochenta; mientras que el anclaje global, tiene que ver con aquellas movilizaciones feministas a lo largo del globo, que refieren a la \#NiUnaMenos, la violencia de género, los pañuelazos argentinos o los veredictos sobre "La Manada". De esta manera, a modo de hipótesis, este movimiento representa una cuarta ola feminista con las particularidades específicas del caso chileno.

La metodología de este artículo es de carácter exploratorio y cualitativo, a partir de lo cual se realizaron entrevistas en profundidad, del tipo historia de vida a más de 15 activistas 11 del reciente movimiento estudiantil que participaron en asambleas y tomas de sus instituciones educativas. Se consideraron estudiantes universitarias y secundarias de Santiago, La Serena y Puerto Montt. También se analizaron fuentes secundarias, como la prensa y entrevistas de activistas en foros o seminarios.

\section{Las olas feministas}

Desde las ciencias sociales, se ha caracterizado el desarrollo del feminismo en Occidente a partir de tres grandes olas o momentos históricos ${ }^{12}$. La primera ola del feminismo

9 José Joaquín Brunner, Guiar el Mercado: Informe sobre la Educación Superior en Chile, Santiago, UDP, 2005.

10 El dínamo, "Las 15 universidades que iniciaron tomas feministas a lo largo del país", 14 de mayo del 2018.

Consultado el 21 de abril del 2019: https:// www.eldinamo.cl/educacion/2018/05/14/las-15-universidadesque-iniciaron-tomas-feministas-a-lo-largo-del-pais/

11 En este artículo solo aparecen citadas 2 entrevistadas por el carácter del artículo.

12 Teresita De Barbieri, “Más de tres décadas de los estudios de género en América Latina”, Revista Mexicana de Sociología, vol 66, número especial oct 2004, p. 197-214; Francisco Longa, “Del antipatriarcado al feminismo: derivas del ethos militante en un movimiento social de la Argentina (2004-2015), Estudios de Género del Colegio de México, 3(5), enero-junio, 2017, p. 57-89. 
consideraría el periodo amplio, donde algunos investigadores señalan que comienza desde principios del siglo XIX, mientras otros afirman que comienza a fines del siglo XIX en los años 1880. Esta ola tendría su final alrededor de los años cuarenta del siglo XX cuando ya muchos países desarrollados cuentan con el derecho de la mujer a votar ${ }^{13}$, y las reivindicaciones estarían asociadas a la inclusión en el cambio de los derechos sociales, principalmente sufragistas y organizaciones feministas ${ }^{14}$. Efectivamente, ese momento histórico varía en función de los procesos democratizadores de cada país, pero se genera de manera transversal en Occidente.

Por consiguiente, la segunda ola del feminismo que se daría a partir de la segunda mitad del siglo XX y que para algunas investigadoras todavía estaría vigente, busca incluir a la mujer en la toma de decisiones y también tener un control más amplio sobre algunos asuntos privados como la igualdad y libertad sexual, y el aborto ${ }^{15}$. Del mismo modo, en esta dimensión de la igualdad de sexos, estaría incluido el control de la fertilidad por parte de las mujeres con la utilización de píldora. Para otros autores, podría graficarse como la conceptualización del pasaje del sexo al género ${ }^{16}$ con estudios como aquellos de Simone de Beauvoir y el segundo sexo, con aquella famosa frase "no se nace mujer, se llega a serlo" 17 y que cuestiona la sociedad patriarcal.

Consecuentemente, la tercera ola feminista representaría, para algunos autores 18 , una nueva generación que buscaría exaltar y visibilizar la diversidad cultural, social, religiosa, racial y sexual. Elementos que se pueden observar en todo el globo, en las marchas del Orgullo gay o "Pride Parade", en ciudades como Nueva York, Río de Janeiro, Bangalore o Hong-Kong. Santiago de Chile no se queda al margen de esta ola y también ha visto florecer este tipo de movilizaciones, como también movimientos por la diversidad sexual.

Asimismo, en el caso particular de Chile, Julieta Kirkwood ${ }^{19}$ interpretó momentos claves del movimiento feminista, los cuales pueden corresponderse tal vez -en algunos aspectos, de formas un poco forzadas- con aquellas olas del feminismo mundial. El primero de esos momentos fue entre 1930 y 1950, cuando la lucha se concentró en la demanda del voto político de las mujeres ${ }^{20}$. Si bien el objetivo fue alcanzado en 1949, recién se puso en práctica en la elección presidencial de 1952. En el marco de dicho movimiento se creó la organización feminista MEMCH (Movimiento pro Emancipación de la Mujer Chilena), pero rápidamente

\footnotetext{
13 Andrea Biswas (2004). "La tercera ola feminista: cuando la diversidad, las particularidades y la diferencia son lo que cuenta". Casa del Tiempo, 6 (68): 65-70.

14 Diana Maffía, "Desafíos actuales del feminismo." Consultado el 7 de mayo del 2019 en:

http:/ / dianamaffia.com.ar/archivos/Desaf\%C3\%ADos-actuales-del-feminismo.pdf

Longa, op cit., $57-89$.

15 Biswas, op cit., 65-70.

16 Longa, op cit., 57-89.

17 Simone de Beauvoir, El segundo sexo, Buenos Aires, Ediciones Siglo Veinte, 1987.

18 Biswas, op cit., 65-70.

19 Julieta Kirkwood, Ser politica en Chile. Las feministas y los partidos, Santiago, FLACSO, 1986.

20 Kirkwood, op cit., 40.
} 
se desintegró cuando varias de sus integrantes pasaron a la clandestinidad por las políticas anticomunistas de Gabriel González Videla. Kirkwood denominó a este momento como “la incorporación político-ciudadana".

El segundo momento importante del movimiento feminista, que a nivel global representa la libertad de la vida privada, en Chile las mujeres lo viven en dictadura. Por lo tanto, el slogan "Democracia en el país y en la casa" busca visibilizar esos mismos conflictos también, pero priorizando ante todo la defensa de los derechos humanos. Los movimientos de mujeres como el llamado "Movimiento Feminista" y el MEMCH 83, buscaron terminar con la represión, violencia y tortura hacia las mujeres, pero no solo hacia ellas. Vale clarificar que el MEMCH (del primer momento), se reorganizó y pasó a llamarse MEMCH 83 encabezado por la propia Julieta Kirkwood21, agrupando a varias organizaciones de mujeres. Asimismo, se crearon otras organizaciones, como la Agrupación de Familiares de Detenidos Desaparecidos (AFDD) que nace a finales de 197422 y es liderada principalmente por mujeres: esposas, hijas y hermanas sobrevivientes ${ }^{23}$. Así es como, la libertad sexual y privada se vio postergada por el contexto de la dictadura chilena y la segunda ola global que se vive en el resto de Occidente emerge con otras particularidades.

Durante los primeros años de la postdictadura, los movimientos feministas que desplegaron toda su fuerza política y contestataria contra la dictadura se fragmentaron y dispersaron ${ }^{24}$. Así es como, por varias razones, el discurso feminista dejó de estar presente no solo en el espacio público, sino también en los debates políticos y los partidos. La investigadora Richard aborda distintas razones que afectan a esta desaparición del discurso feminista durante la transición. La primera de esas razones refiere a que las mujeres ganaron más espacios de representación pública en la sociedad, por lo cual, muchas feministas dejaron los movimientos sociales por una participación desde las instituciones públicas. En segundo lugar, la creación del SERNAM (Servicio Nacional de la Mujer) organismo centrado en coordinar las políticas públicas de igualdad y no discriminación sexual, no tuvo un enfoque crítico suficiente frente a los temas de género. En tercer lugar, la "democracia de los acuerdos" propia de los años de la Concertación, obligó a mesurar los discursos confrontaciones y a rebajar el acento de debates conflictivos dentro de la misma coalición, como el aborto o el divorcio. Por último, la instalación de un modelo social que privilegió la técnica y la eficiencia desplazando lo "feminista-militante" hacia una mirada profesionalizante, permitió darles mayor preponderancia a organizaciones como las ONG's y organismos similares por sobre las orgánicas militantes. Así es como la voz feminista fue

\footnotetext{
21 Kirkwood, op cit.

22 Paola Díaz y Carolina Gutiérrez, “Resistencias en dictadura y en post-dictadura: la acción colectiva de las agrupaciones de familiares de detenidos desaparecidos, Pandora: revue d'études hispaniques, (8), 2008, p. 187-204.

23 Esta agrupación de moviliza tanto en la dictadura como en la postdictadura. En la dictadura generan distintos actos de resistencia, tales como peticiones, declaraciones y cartas abiertas; y manifestaciones, como marchas, sit-in, conmemoraciones o huelgas de hambre. Se articulaban con la Vicaría de la Solidaridad y abogados de derechos humanos, entre otras organizaciones.

24 Nelly Richard, Feminismo, género y diferencia(s), Santiago, Palinodia, 2018.
} 
perdiendo intensidad en el escenario de lo público ${ }^{25}$ y los movimientos feministas se desdibujan durante este periodo.

En la postdictadura, particularmente en la década de los 2000, hay algunas movilizaciones aisladas de organizaciones feministas contra la prohibición de la píldora del día después ${ }^{26}$. Aquí se organizan tanto organizaciones de mujeres jóvenes como también organizaciones creadas en dictadura durante los ochenta. Contra estas protestas, se organizan grupos "provida" que buscan limitar la venta de estas pastillas ${ }^{27}$. Del mismo modo, con la llegada de Michelle Bachelet a la presidencia, vuelven a resonar muchas de las temáticas feministas en el espacio de lo público y el tema de la píldora vuelve a la palestra y grupos conservadores también se oponen a su distribución ${ }^{28}$.

Es importante destacar el hecho de contar con una primera mujer Presidenta, además que ella perfila como una líder política distinta, que además es divorciada, fue exiliada y torturada. La figura de Michelle Bachelet seduce un tipo de electorado distanciado de la política: mujeres de mediana edad o mayores que no se sienten representadas por los políticos. Así es como, durante la investidura presidencial de Bachelet, cientos de mujeres salen a las calles con una banda presidencial para hacerlas partícipes de este momento. A pesar del rol de Bachelet, los enclaves autoritarios legados por la dictadura y la institucionalidad de los gobiernos de la Concertación, limitan el desarrollo de los derechos de las mujeres ${ }^{29}$.

Algunas intelectuales y académicas han señalado que estamos frente a una tercera ola del feminismo. Tal es el caso de Kemy Oyarzún, académica, quien afirma que esta es una nueva ola del feminismo que lucha por las identidades y contra una sociedad patriarcal ${ }^{30}$. Del mismo modo, la socióloga y coordinadora del Observatorio de Género y Equidad, Teresa Valdés, sostiene que "esta es la tercera ola feminista (...) el actual movimiento saca del espacio privado la violencia hacia la mujer y alerta que ocurre en el espacio público donde por el hecho de ser mujer estás expuesta a un montón de violencia y acoso" 31 .

${ }^{25}$ Richard, op. cit.

${ }^{26}$ Luna Follegati, “El feminismo se ha vuelto una necesidad: movimiento estudiantil y organización feminista (2000-2017)", Anales de la Universidad de Chile, no 14, 2018.

27 Cecilia Baeza y Camila Ponce, “De la "Loi des 3 causes" au plus grand mouvement féministe de l'histoire du Chili : dynamiques, actrices, et nouvelles subjectivités", Problèmes de l'Amerique Latine, en prensa.

${ }_{28}$ Fabiola Miranda, "La judicialización del caso de la píldora del día después en Chile: las tensiones sobre el rol de la mujer y la cuestión técnica". Halshs archives ouvertes, 2013, consultado el 3 de agosto de 2019 en:

https://halshs.archives-ouvertes.fr/halshs-00787526/document

${ }^{29}$ Miranda, op. cit.

30 Kemy Oyarzún en: Hugo Guzmán, “Esta tercera ola es la lucha por las identidades”, El Siglo, 29 de mayo del 2018, Consultado el 8 de mayo del 2019: http:// www.elsiglo.cl/2018/05/29/esta-tercera-ola-es-la-lucha-porlas-identidades/

31 Teresa Valdés en: Paulina Sepúlveda, “Feminismo chileno vive su revolución más importante en 40 años”, La Tercera, 20 de mayo 2018, consultado el 1 de mayo de 2019 en:

https:// www.latercera.com/tendencias/noticia/feminismo-chileno-vive-revolucion-mas-importante-40$\underline{\operatorname{anos} / 172111 /}$ 
A nivel internacional, algunas autoras han señalado que estamos en una cuarta ola feminista. Así lo declara Chamberlain ${ }^{32}$ definiéndola como una ola que exige la justicia a las mujeres, que rechaza particularmente el acoso sexual y la violencia hacia las mujeres. Por otro lado, Cochrane ${ }^{33}$, da cuenta que esta ola parece algo nuevo y está definida por la tecnología, que permite que las mujeres se construyan como sujetas empoderadas y populares en el marco de un movimiento online. Ejemplos que podemos observar a partir del descontento que se genera luego de las denuncias de acoso a partir del hashtag \#MeToo realizado a través de las plataformas online.

Del mismo modo, estos elementos los podemos encontrar en el caso chileno, puesto que es un movimiento que crece gracias a las denuncias a académicos en distintas universidades chilenas, y remite a la violencia de género y acoso sexual. Sin embargo, este movimiento trae otros elementos consigo, como es reinscribirse en la densa trama histórica que ha tejido por años el feminismo en nuestro país, también surge y se estructura en los patios y aulas de las universidades chilenas, y dialoga con los movimientos feministas latinoamericanos como el \#NiUnaMenos o los pañuelazos argentinos. Este movimiento sitúa en el centro de la escena y como elementos de lucha, al mundo privado y al cuerpo, desacralizando y re-sexualizando así las vulvas femeninas, mostrándolas grandes y coloridas en las marchas, tal como podemos ver en la imagen $\mathrm{N}^{\circ} 1$ donde la vulva tiene colores fuertes y llamativos, y se muestra grande sin ningún texto que la acompañe porque se la reivindica a ella misma, completa, sin tabús en el espacio público.

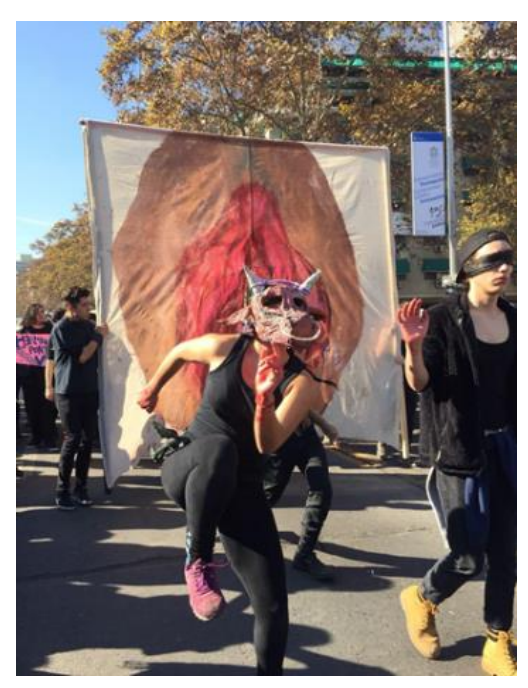

Asimismo, las mujeres salen a marchar desnudándose y dejando de ser un objeto que puede ser comprendido como sexual o como víctima de acoso. Esta cuarta ola da cuenta que las luchas no son propias del mundo offline $u$ online: se disputan en el espacio público, las instituciones (en este caso, educativas), y también en las redes sociales donde emergen muchas mujeres activistas y que se vuelven protagonistas en este proceso de politización feminista.

Foto. Marcha feminista de Santiago, miércoles 6 de junio 2018. Fuente: autora

\section{Anclajes históricos y globales.}

El movimiento estudiantil parecía completamente centrado en las temáticas del endeudamiento y el lucro en las universidades de educación superior.

\footnotetext{
32 Prudence Chamberlain, The feminist fourth wave: Affective temporality. Houndmills, UK, Palgrave Macmillan, 2017.

33 Kira Cochrane, All the rebel women: The rise of the fourth wave of feminism. Londres, Guardian Books, Vol. 8. 2013.
} 
Justamente, posterior al movimiento de 2011 emergen dos agrupaciones concentradas en esta temática, la primera de ellas busca la condonación de la deuda y se denomina "Deuda educativa", mientras que la segunda busca que ningún endeudado por la educación vuelva a pagar y se llaman "No pago". Paralelamente, se crean Secretarías de Género en las distintas universidades para trabajar sobre el acoso en las facultades, pero las demandas feministas estaban presentes de manera latente. Tal como lo señala una activista feminista de la Universidad de Chile:
"Yo creo que mi experiencia en el movimiento feminista, y lo que viene siendo la construcción de hace varios años de esto que se ha desencadenado, que parece haber empezado hace tres meses, pero en realidad viene construyéndose hace mucho tiempo, tiene que ver con la experiencia de ser estudiante. Ser estudiante y ser parte de las organizaciones estudiantiles en distintos espacios (en algún momento a las feministas nos tenían en espacios paralelos), en comisiones, como si la temática del género, la mal llamada temática del género, fuera una particularidad y algo sectorial. Fue bien curioso vivir todo este proceso en que la política feminista en un momento corría por un carril separado al de la política del movimiento estudiantil, hasta que hoy ya se toma la agenda política del país desde el movimiento estudiantil. Es bien interesante. A mí me tocó ser parte de la Secretaría de Género de la FECH durante los años en que se trabajó el protocolo para denunciar el acoso que se aprueba a fines del 2016 y 2017 y el proceso del decreto Mara Rita, el reglamento en torno al uso y el reconocimiento del nombre social de las y los estudiantes trans, en particular desde mi experiencia personal de ser una estudiante trans de la Universidad de Chile" 34.

En este relato corresponde al de una activista feminista, transgénero y militante de Izquierda Autónoma ${ }^{35}$, quien además fue vocera de la "Coordinadora 8 de marzo" y que acaba de ser elegida este año 2019, Presidenta de la Federación de Estudiantes de la Universidad de Chile. Aquí se evidencia lo mencionado anteriormente. Este no es un movimiento que no tiene un anclaje y vinculación con los movimientos anteriores. Efectivamente, las problemáticas feministas eran consideradas "sectoriales", por lo que a veces no dialogaban necesariamente con el resto de los estudiantes, pero es un proceso que comienza a construirse en los espacios universitarios, que son justamente aquellos que permiten esta socialización política ${ }^{36}$. La socialización política que en un comienzo es para formarse políticamente, aquí la activista lo refiere a una formación feminista, pero esta formación

\footnotetext{
34 Entrevista a Emilia Schneider en: Alejandra Araya, “Nuevas voces, nuevos enfoques y nuevos temas en la discusión feminista", Anales de la Universidad de Chile, (14), 217-244. 220.

35 Izquierda autónoma es una organización política de izquierda extra parlamentaria, que operaba principalmente en las Universidades chilenas. Esta agrupación tiene una herencia autonomista del Movimiento SurDa y del movimiento de estudiantes por la Reforma. Algunos de sus principales líderes estudiantiles fueron Gabriel Boric y Francisco Figueroa, ambos de la Federación de la Universidad de Chile (FECH). En 2016 se produce un quiebre entre dos facciones: la primera liderada por Carlos Ruiz; y la segunda dirigida por Boric. En 2018, esta organización que integra el Frente Amplio, se fusiona con Poder Ciudadano bajo el nombre de Comunes. Ver: Víctor Muñoz, "Generaciones: juventud universitaria e izquierdas políticas en Chile y México (Universidad de Chile-UNAM 1984-2006)". Santiago, LOM ediciones, 2011.

36 Camila Ponce, "La socialización política en el aula: Comparación entre las movilizaciones de Francia y Chile." Revista Latinoamericana de Ciencias Sociales, Niñez y Juventud, Volumen 11, número 2, 2013, 603-615.
} 
despliega distintos elementos: por una parte, una formación política, como también una construcción feminista. Este movimiento tiene algunos hitos previos, como la lucha por la venta de la píldora del día después que había sido retirada por las farmacias, tal como lo señala una activista:

"En la universidad hicimos muchas cosas de carácter feminista, desde escritos, colectivos y reivindicaciones, principalmente el 8 de marzo. También generamos movilizaciones específicas frente al ex congreso cuanto querían impedir la venta de la píldora del día después, nos articulamos con otras feministas jóvenes egresadas y repartimos informativos para instruir a las mujeres en cómo hacer una píldora del día después. Los provida [antiaborto] iban a gritarnos "asesinas" mientras repartíamos esto" 37.

Este relato es de una activista que forma parte del movimiento estudiantil de principios del 2000 por lo tanto las demandas son otras. Las jóvenes que se declaran como feministas estaban activas, pero en ese periodo las energías están puestas en distintos frentes, como era en este caso, la píldora del día después, la lucha por una mejor educación y generar mayor participación de los estudiantes.

En la actualidad, las estudiantes secundarias que participan en las movilizaciones, buscan también reivindicar y traer al presente a aquellas feministas de los ochenta, que lucharon en la dictadura. De esta manera, ellas aprenden y participan más activamente del movimiento. El hecho de recordar y traer al presente las historias de feministas de los ochenta, permite darle continuidad al movimiento feminista y generar este anclaje histórico. Tal como lo señala esta estudiante secundaria:

“Acá en la toma somos súper pocas las que participamos y las cabras no saben y votan por
monedas. Por eso me metí, para aprender y que las otras compañeras aprendieran. En el
colectivo hacíamos reeducación interna, también hicimos lienzos, el año pasado hicimos
talleres de educación, de feminismo, de conmemoración al 11 de septiembre. Este año
hicimos una actividad de una detenida desaparecida que murió, también hicimos el
noviembre feminista, de mujeres que deberían reconocerse y no se reconocen, pero es difícil
en el liceo porque la administración es de derecha. La dirección nos rompía los lienzos"38.

Uno de los elementos sobresalientes de este movimiento, es que tiene un fuerte anclaje histórico. Puesto que, por un lado, se observa una explícita y clara reivindicación del movimiento feminista de los años ochenta, realzando el legado y el trabajo de las mujeres que lucharon durante la década de los ochenta en dictadura, y trayendo al presente a muchas mujeres que fueron violadas, torturadas e invisibilizadas en este periodo. Esta idea es posible constatarla a partir de las diferentes instalaciones que se realizaron en las universidades durante el último 11 de septiembre. Por ejemplo, en la Universidad de Valparaíso se vieron imágenes de mujeres embarazadas y la pregunta sobre sus hijos

37 Entrevista realizada en el marco de esta investigación, efectuada en julio de 2018. Javiera es anarquista, es estudiante de la Pontificia Universidad Católica de Chile.

38 Entrevista realizada en el marco de esta investigación, efectuada en julio de 2018. Elena es activista feminista, es estudiante del Liceo 7 de Providencia. 
desaparecidos, mientras que en la Universidad Católica Silva Henríquez se desplegaron relatos anónimos de mujeres torturadas, como también imágenes de desaparecidos. Todo esto tiene sentido cuando en Chile se ha desatado un importante debate sobre la memoria y los derechos humanos a causa de la salida del Ministro de Cultura, Mauricio Rojas, quien desacreditó el Museo de la Memoria y debió renunciar a su cargo en agosto del 201839; cuando varios torturadores juzgados por crímenes de lesa humanidad fueron puestos en libertad por "razones humanitarias" 40.

Este anclaje histórico no desatiende los vínculos con el presente y la postdictadura. De esta forma, el movimiento estudiantil feminista dialoga con los movimientos estudiantiles precedentes -como aquel del 2011 y del 2006- puesto que incorpora demandas como la educación no sexista y el lenguaje inclusivo a las demandas históricas del movimiento estudiantil como son la educación gratuita, el fin al lucro y la educación de calidad. Las estudiantes buscan así debatir sobre una educación para todes y la generación de protocolos contra el acoso en todas sus formas. Asimismo, este movimiento tampoco está desarticulado ni desatiende las luchas contra el femicidio y los cuerpos maltratados. De este modo, se incorpora al movimiento internacional de la \#NiUnaMenos. Esta idea se traduce en los distintos velatones ${ }^{41}$ que se realizaron en muchas universidades y espacios públicos recordando a las mujeres asesinadas por sus parejas. Igualmente, cada cierto tiempo emergen las demandas por el derecho al aborto libre, seguro y gratuito para todas las mujeres; en clara sintonía con el masivo movimiento de los pañuelos verdes en Argentina.

El movimiento feminista tiene distintos momentos y procesos que funcionan para activar movilizaciones de mayor envergadura y movilizar actrices de distintos espacios, tal como lo señala esta activista y líder del movimiento estudiantil feminista:

"Viví bien de cerca ese proceso en que se amplía ese horizonte del movimiento feminista, que fue de condenar la violencia de género a un cuestionamiento más estructural de la sociedad cuando se transforma la consigna de "Ni una menos" a "Mujeres trabajadoras por la precarización de la vida" "42

\footnotetext{
39 Mauricio Rojas duró solo 4 días como Ministro de Cultura luego que se filtraran sus dichos contra el museo de la Memoria, donde señalaba en un libro que este espacio era un montaje. El 13 de agosto del 2018 el presidente Piñera aceptó su renuncia. Ver: Infobae, "Mauricio Rojas criticó al museo de la memoria de Chile y debió renunciar como ministro de cultura", 13 de agosto 2018, Consultado el 7 de mayo del 2019 en: https://www.infobae.com/america/cultura-america/2018/08/13/mauricio-rojas-critico-al-museo-de-lamemoria-de-chile-y-debio-renunciar-como-ministro-de-cultura/ 40 Martín Espinoza, “¿Quiénes son y qué hicieron los liberados de Punta Peuco?”, Diario U Chile, 1 de agosto 2018, Consultado el 7 de mayo del 2019 en: https:/ / radio.uchile.cl/2018/08/01/quienes-son-y-que-hicieronlos-liberados-de-punta-peuco/

41 Forma de acción colectiva que consiste en utilizar muchas velas con el objetivo de recordar. Práctica utilizada particularmente en la postdictadura durante los 11 de septiembre.

42 Entrevista a Emilia Schneider en: Araya, op. cit., 220.
} 
En este relato, la activista da cuenta no solo de cómo se abordan nuevos elementos a partir de la consigna global de la \#NiUnaMenos y las demandas previas a la gran marea feminista del 2018, sino que permite dar cuenta de todo un proceso al interior de las universidades, donde la discusión sobre las demandas feministas no era algo para nada nuevo, sino que estaba invisibilizadas por otras demandas que tenían más resonancia en lo público, como es el caso del movimiento estudiantil. Asimismo, la universidad se revela como un espacio de experiencia y subjetivación política importante, no solo para volverse activista, sino también feminista. En estos espacios las y los estudiantes construyen debates y colectivos donde se socializan experiencias y se reconstruyen relatos que permiten transformar sus trayectorias políticas. Asimismo, el relato de Araceli Farías, estudiante de la Pontificia Universidad Católica de Chile y vicepresidenta de la Federación de Estudiantes de esa institución (FEUC), permite también dar cuenta de la dimensión global y del rol de las emociones en esta movilización:

\begin{abstract}
"si bien, los temas de los protocolos se vienen tocando hace mucho tiempo, que se ha peleado incansablemente, tal vez desde un nicho más personalizado, en mujeres que algo más empatizado por todas las comunidades universitarias, yo creo que este año algo que hizo que se acumulara mucha rabia y que hizo reventar todo esto fue el caso de "la manada" en España, porque por la misma fecha, en el sur, en la Universidad Austral, deciden tomarse la universidad. Ahí empiezan a brotar las tomas feministas en distintos planteles educativos, lo que alcanzó un revuelo increíble y sentó las bases para que se pudieran paralizar los espacios, para que las comunidades educativas pudieran hablar del tema. También fue un llamado a las mismas estudiantes a tomar responsabilidad y que se pudieran llevar a cabo estas discusiones con nuestros profesores, funcionarios, compañeros y también en los espacios sociales con nuestra familia, amigos" 43
\end{abstract}

Tal como se enunciaba en un comienzo del artículo, el carácter global del movimiento es uno de los elementos centrales para generar movilización y desatar el descontento de las activistas. El rol de las emociones tampoco debe ser desatendido, tal como mencionan autores como Jasper ${ }^{44}$, los grupos pueden muchas veces fortalecerse cuando comparten ciertas emociones, con relación a eventos, lo que Jasper denomina "emociones compartidas y recíprocas" 45 . Así es como, la rabia y el sentimiento de injusticia que desata la sentencia del grupo "La Manada" en España, es movilizador, no solo en el país europeo sino también en Chile. Finalmente, se observa que este tipo de injusticias y el sentimiento de imponencia es transnacional y moviliza a activistas más allá de los límites de las fronteras. Lo mismo ocurre con el femicidio en el caso chileno, que permite articular activistas de distintos tipos de feminismos y organizaciones políticas, además las convocatorias son de carácter intergeneracional.

43 Entrevista a Araceli Farías en: Araya, op cit., 234.

44 James Jasper, "Emotions and Social Movements: Twenty Years of Theory and Research", Annual Review of Sociology, volumen 37, 2011, pp. 285-304.

45 James Jasper, “The emotions of protest: affective and reactive emotions in and around social movements", Soc. Forum 13, 1998, 397-424. 


\section{Conclusiones}

A partir de este artículo, es posible responder las distintas interrogantes planteadas en un comienzo. Efectivamente este movimiento representa una cuarta ola feminista con una multiplicidad de demandas y con elementos que pertenecen a otras olas feministas, que van desde mayores libertades sexuales y aborto libre y también visibilizar el mundo privado, que serían propias de la segunda ola; o la visibilización de las identidades, que sería propio de la tercera ola. Asimismo, también se encuentran elementos propios de la cuarta ola, y los elementos específicos del espacio-tiempo y la era global en la cual se inscribe este movimiento. Estos elementos refieren particularmente al acoso y a la violencia contra la mujer, y a la organización a partir de plataformas online. Por lo tanto, son elementos que se superponen y que dialogan entre sí, recuperando elementos del pasado e incorporando otros nuevos también. Este es un movimiento que recupera tradiciones y memorias procedentes de aquellos movimientos de mujeres de los años ochenta, y genera redes y diálogos para incorporar esos relatos en este nuevo movimiento.

Este es un movimiento de carácter global, que se inscribe en la densa trama de movilizaciones post 2011, donde el rol de las redes es fundamental, y donde la organización se realiza a partir de espacios online y offline. Las estudiantes además se movilizan por una indignación que traspasa las fronteras y que genera la necesidad de organizarse y alzar la voz. Las activistas de esta nueva ola feminista, además incorporan elementos de movilizaciones precedentes y también de aquellas que se desarrollan paralelamente más allá de las fronteras del Estado Nación.

Asimismo, como estas movilizaciones se originaron en el seno de las instituciones universitarias, también es un movimiento que incorpora ese tipo de demandas en su discurso y sus demandas. La educación -en este caso no sexista- estaría en el corazón del relato de las activistas, pero a partir de este año 2019, a partir del día de la mujer del 8 de marzo donde en Santiago se generaría un cambio. Gracias a la marcha del 8 de marzo, la marcha feminista más grande de la historia del país, con cientos de mujeres en las calles, es posible ver como las demandas toman dimensiones intersectoriales, tal como señalarían autoras como Crenshaw o Nash 46 incorporando a las mujeres lesbianas, mujeres migrantes, mujeres trabajadoras, mujeres de la tercera edad, mujeres mapuche y también incorporar aquellas demandas del movimiento LGTBIQ e ir más allá de los paradigmas binarios ${ }^{47}$ y los constructos de roles.

En conclusión, se evidencian a partir de las entrevistas con activistas, elementos que requieren ser analizados y abordados de manera específica, en futuras investigaciones sobre este movimiento feminista, como son todas aquellas emociones emanadas a partir de las

\footnotetext{
${ }^{46}$ Nash, Jennifer C. Re-thinking intersectionality. Feminist review, 2008, vol. 89, no 1, p. 1-15; Kimberle Crenshaw, Demarginalizing the intersection of race and sex: a black feminist critique of antidiscrimination doctrine, feminist theory, and antiracist politics, University of Chicago Legal Forum, 1989.

47 Judith Butler, El género en disputa: El feminismo y la subversión de la identidad, Madrid, Paidós, 2007.
} 
movilizaciones: la rabia, la ira, la indignación, son emociones que están presentes en las activistas y que generan la necesidad de movilizarse y organizarse. Por ello, es fundamental abordar todas estas dimensiones. Paralelamente, el carácter performativo en la protesta, el rol del cuerpo como lienzo y como las activistas dejan de lado las demandas de un colectivo, para mostrar sus propias individualidades en los carteles que portan en las manifestaciones, son elementos que están tensionando y generando interrogantes para ser desarrolladas en una futura investigación.

\section{Bibliografía}

Alberto Melucci, Social movements and the democratization of everyday life, Londres, Verso, 1988.

Alejandra Araya, "Nuevas voces, nuevos enfoques y nuevos temas en la discusión feminista", Anales de la Universidad de Chile, (14), 217-244. 220.

Andrea Biswas, "La tercera ola feminista: cuando la diversidad, las particularidades y la diferencia son lo que cuenta". Casa del Tiempo, 6 (68), 2004, 65-70.

Camila Ponce, Des livres à la rue: la transformation culturelle et politique des jeunes militants chiliens à partir des mobilisations étudiantes de 2011, Paris, 2017, Tesis defendida en la École des Hautes Études en Sciences Sociales de Paris.

Camila Ponce, "La socialización política en el aula: Comparación entre las movilizaciones de Francia y Chile." Revista Latinoamericana de Ciencias Sociales, Niñez y Juventud, Volumen 11, número 2, 2013, 603-615.

Cecilia Baeza y Camila Ponce, "De la "Loi des 3 causes" au plus grand mouvement féministe de l'histoire du Chili: dynamiques, actrices, et nouvelles subjectivités", Problèmes de l'Amerique Latine, en prensa.

Charles Tilly y Sidney Tarrow, Politique(s) du conflit. De la grève à la révolution, Paris, Presse de Sciences Po, 2008.

Diana Maffía, "Desafíos actuales del feminismo." Consultado el 7 de mayo del 2019 en: http://dianamaffia.com.ar/archivos/Desaf\%C3\%ADos-actuales-del-feminismo.pdf

Fabiola Miranda, "La judicialización del caso de la píldora del día después en Chile: las tensiones sobre el rol de la mujer y la cuestión técnica". Halshs archives ouvertes, 2013, consultado el 3 de agosto de 2019 en: https://halshs.archives-ouvertes.fr/halshs$\underline{00787526 / \text { document }}$ 
Francisco Longa, "Del antipatriarcado al feminismo: derivas del ethos militante en un movimiento social de la Argentina (2004-2015), Estudios de Género del Colegio de México, 3(5), enero-junio, 2017, p. 57-89.

Hanspeter Kriesi, "New social movements and the new class in the Netherlands", American Journal of Sociology, 94(5), 1989, 1078-1116.

James Jasper, "Emotions and Social Movements: Twenty Years of Theory and Research", Annual Review of Sociology, volumen 37, 2011, pp. 285-304.

James Jasper, "The emotions of protest: affective and reactive emotions in and around social movements", Soc. Forum 13, 1998, 397-424.

José Joaquín Brunner, Guiar el Mercado: Informe sobre la Educación Superior en Chile, Santiago, UDP, 2005.

Julieta Kirkwood, Ser politica en Chile. Las feministas y los partidos, Santiago, FLACSO, 1986.

Judith Butler, El género en disputa: El feminismo y la subversión de la identidad, Madrid, Paidós, 2007.

Kimberle Crenshaw, Demarginalizing the intersection of race and sex: a black feminist critique of antidiscrimination doctrine, feminist theory, and antiracist politics, University of Chicago Legal Forum, 1989.

Kira Cochrane, All the rebel women: The rise of the fourth wave of feminism. Londres, Guardian Books, Vol. 8. 2013.

Luna Follegati, "El feminismo se ha vuelto una necesidad: movimiento estudiantil y organización feminista (2000-2017)", Anales de la Universidad de Chile, no 14, 2018.

Manuel Antonio Garretón, Incomplete Democracy, North Carolina, Chapel Hill, 2003.

Nash, Jennifer C. Re-thinking intersectionality. Feminist review, 2008, vol. 89, no 1, p. 1-15

Nelly Richard, Feminismo, género y diferencia(s), Santiago, Palinodia, 2018.

Paola Díaz y Carolina Gutiérrez, "Resistencias en dictadura y en post-dictadura: la acción colectiva de las agrupaciones de familiares de detenidos desaparecidos", Pandora: revue d'études hispaniques, (8), 2008, p. 187-204.

Prudence Chamberlain, The feminist fourth wave: Affective temporality. Houndmills, UK, Palgrave Macmillan, 2017. 
Sandra Vera, "Cronología del conflicto: El movimiento estudiantil en Chile, 2011", Anuario del Conflicto Social 2011, 2012, 247-251 .

Sidney Tarrow, Struggling to reform: Social movements and policy change during cycles of protest, Center for International Studies, Cornell University, 1983.

Simone de Beauvoir, El segundo sexo, Buenos Aires, Ediciones Siglo Veinte, 1987.

Teresita De Barbieri, "Más de tres décadas de los estudios de género en América Latina", Revista Mexicana de Sociología, vol 66, número especial oct 2004, p. 197-214.

Víctor Muñoz, "Generaciones: juventud universitaria e izquierdas políticas en Chile y México (Universidad de Chile-UNAM 1984-2006)". Santiago, LOM ediciones, 2011.

\section{$\underline{\text { Prensa }}$}

Antonia Salas, "Universidad Austral, el plantel donde se gestó la primera toma feminista en Chile y un protocolo contra el acoso", 9 de junio de 2018: Consultado el 22 de abril del 2019: https:// www.emol.com/noticias/Nacional/2018/06/09/909169/Universidad-Austral-elplantel-donde-se-gesto-la-primera-toma-feminista-en-Chile-y-protocolo-contra-el$\underline{\text { acoso.html }}$

Camila Mardones, "Movilizaciones en liceos emblemáticos", La Tercera, 28 de mayo de 2018. Consultado el 21 de abril de 2019:

https://www.latercera.com/nacional/noticia/movilizacion-liceosemblematicos/183347/\#

Camila Ossandón y José Tomás Tenorio, "Sexo, mentiras y denuncias: la Facultad de Filosofía y Humanidades de la Universidad de Chile y los casos de acosos y anuncios", El Mostrador, 27 de diciembre de 2016. Consultado el 21 de abril de 2019 en: https:// www.elmostrador.cl/noticias/pais/2016/12/27/sexo-mentiras-y-denuncias-lafacultad-de-filosofia-y-humanidades-de-la-universidad-de-chile-y-los-casos-de-acoso-yabusos/

Hugo Guzmán, "Esta tercera ola es la lucha por las identidades", El Siglo, 29 de mayo del 2018, Consultado el 8 de mayo del 2019: http:/ / www.elsiglo.cl/2018/05/29/esta-terceraola-es-la-lucha-por-las-identidades/

El dínamo, "Las 15 universidades que iniciaron tomas feministas a lo largo del país", 14 de mayo del 2018. Consultado el 21 de abril del 2019:

https://www.eldinamo.cl/educacion/2018/05/14/las-15-universidades-que-iniciarontomas-feministas-a-lo-largo-del-pais/ 
Infobae, "Mauricio Rojas criticó al museo de la memoria de Chile y debió renunciar como ministro de cultura", 13 de agosto 2018, Consultado el 7 de mayo del 2019 en:

https:// www.infobae.com/america/cultura-america/2018/08/13/mauricio-rojas-criticoal-museo-de-la-memoria-de-chile-y-debio-renunciar-como-ministro-de-cultura/

Martín Espinoza, “QQuiénes son y qué hicieron los liberados de Punta Peuco?”, Diario U Chile, 1 de agosto 2018, Consultado el 7 de mayo del 2019 en:

https:/ / radio.uchile.cl/2018/08/01/quienes-son-y-que-hicieron-los-liberados-de-puntapeuco/

Paulina Sepúlveda, "Feminismo chileno vive su revolución más importante en 40 años", La Tercera, 20 de mayo 2018, consultado el 1 de mayo de 2019 en:

https:// www.latercera.com/tendencias/noticia/feminismo-chileno-vive-revolucion-masimportante-40-anos/172111/

\section{$\underline{\text { Entrevistas }}$}

Elena es activista feminista, es estudiante del Liceo 7 de Providencia. Entrevista realizada en el marco de esta investigación, efectuada el 12 de julio de 2018.

Javiera es anarquista, es estudiante de la Pontificia Universidad Católica de Chile. Entrevista realizada en el marco de esta investigación, efectuada el 17 de julio de 2018. 